\title{
REVIEW
}

\section{Bone marrow and bone: a functional unit}

\section{J E Compston}

Department of Medicine, Box 157, University of Cambridge School of Clinical Medicine, Addenbrooke's Hospital, Hills Road, Cambridge CB2 2QQ, UK

(Requests for offprints should be addressed to J E Compston; Email: jec1001@cam.ac.uk)

\begin{abstract}
Bone and bone marrow, although often regarded as separate systems, function as a single unit. Cells in the bone marrow are the precursors of bone remodelling cells and exert an important regulatory role both on their own development and the remodelling process, acting as mediators for the effects of systemic and local factors. Other cells, such as immune cells and megakaryocytes, also contribute to the regulation of bone cell development and activity. Many diseases that affect the bone marrow have
\end{abstract}

profound effects on bone, involving interactions between abnormal and normal marrow cells and those of bone. Although recent advances in bone physiology have produced new insights into the relationship between bone marrow and bone cells, much remains to be learnt about the mechanisms by which marrow and bone act in synergy to regulate bone remodelling, both in health and disease. Journal of Endocrinology (2002) 173, 387-394

\section{Introduction}

Bone and bone marrow are anatomically contiguous and exhibit marked functional interdependence. Bone marrow contains haematopoietic and non-haematopoietic stem cells from which osteoclasts and osteoblasts respectively originate, the latter being closely involved in the regulation of osteoclastogenesis. In addition, non-osteogenic marrow cells such as megakaryocytes and lymphocytes contribute to the regulation of bone remodelling. The blood supply of bone and bone marrow are directly connected, venous sinuses in the marrow receiving arterial blood from the nutrient arteries of bone and the periosteal capillary network, the latter connecting with the sinuses through the Haversian canals (Brookes 1961). Angiogenesis in the bone marrow is closely associated with osteogenesis in developing and mature bone (Horner et al. 2001) and there is a close association both in health and disease between skeletal blood flow and bone turnover (Van Dyke 1967). The structural and functional heterogeneity of the human skeleton is related to marrow composition and many diseases affecting bone marrow have profound effects on bone remodelling and structure.

\section{Age-related changes in marrow composition and their relationship to bone remodelling}

At birth, virtually all bone marrow is haematopoietic (red marrow) but subsequently this is replaced by fatty or yellow marrow; overall there is an approximately $10 \%$ decrease in bone marrow cellularity for each decade of life. These changes, however, exhibit considerable skeletal heterogeneity, so that at the age of 70 years vertebral bone marrow cellularity is in the region of $30 \%$ whereas, in the shaft of long bones, haematopoiesis disappears completely around the age of 20 years (Custer 1949). There is evidence that the rate of bone turnover is related to marrow composition, higher rates being found in cancellous bone at sites of haematopoietic marrow than where fatty marrow predominates (Krempien et al. 1978, Eventov et al. 1991). The higher rates of bone turnover at sites of persistent haematopoiesis are associated with increased skeletal blood flow (Van Dyke 1967), consistent with the close anatomical association in marrow of venous sinuses and haematopoietic cells.

The nature of the relationship between age-related changes in marrow composition and bone mass has not been clarified. Increased numbers of adipocytes have been observed in bone marrow both in osteoporosis and agerelated bone loss (Meunier et al. 1971, Rozman et al. 1989), but this may reflect the increase in marrow space and reduction in haematopoietic tissue rather than indicating a direct causal link. Alternatively, increased marrow adiposity may be directly linked to reduced osteogenic potential, reflecting a switch in the balance of commitment of stem cells from osteoblasts to adipocytes. Relevant to this issue is the maintenance of bone mass in the shaft of long bones in young adults despite the exclusive presence 
of yellow marrow; it is likely that in these weight-bearing bones, mechanical factors acting directly on bone are predominantly responsible for maintaining bone mass, whereas at axial sites the responsiveness of cells in the bone marrow to systemic hormones is a major determinant of skeletal homeostasis. Thus, although osteoclast precursors circulate in peripheral blood (Fujikawa et al. 1996), providing a potential route of access to bone in the absence of red marrow, there is less evidence that this is true for osteoblast precursors.

\section{The origin of bone cells}

Osteoclasts are derived from haematopoietic stem cells of the monocyte/macrophage lineage (Teitelbaum 2000) whilst osteoblasts originate from pluripotent stromal stem cells, which have the capacity to differentiate into osteoblasts, adipocytes, chondrocytes, myoblasts or fibroblasts (Owen 1988). The commitment, proliferation and differentiation of bone cell precursors are regulated by multiple factors, including cytokines, growth factors, systemic hormones and transcriptional regulators. Bone marrow cells are responsible for the production of many paracrine and autocrine bone regulatory factors and the stromal cell population is essential for normal osteoclastogenesis. Conversely, growth factors released by bone cells are likely to play an important role in haematopoiesis, although this has been less well studied. In addition, cell-cell and cellmatrix interactions are responsible for contact between stromal/osteoblastic cells and osteoclast precursors in the marrow and for the migration of bone precursor cells to the bone surface; these processes involve a number of adhesion molecules including integrins, selectins and cadherins.

\section{Regulation of osteoclast development and activity}

Bone marrow cells are closely involved in the regulation of osteoclast development and activity. Marrow mononuclear cells of the monocyte/macrophage lineage produce interleukin (IL)-1 and tumour necrosis factor- $\alpha$ (TNF $\alpha$ ), cytokines with potent stimulatory effects on osteoclastogenesis and osteoclast activity (Jilka 1998, Pacifici 1999, Compston 2001). These effects are mediated via the production, by marrow stromal cells and osteoblasts, of receptor activator of NFKB ligand (RANKL), IL-6, IL-11, macrophage colony-stimulating factor (M-CSF) and granulocyte-macrophage colony-stimulating factor (GMCSF) (Tanaka et al. 1993, Manolagas \& Jilka 1995, Yasuda et al. 1998). The stimulatory effects of IL-6 and IL-11 on osteoclastogenesis are mediated, at least in part, by the activation of receptor expression in stromal cells (Udagawa et al. 1995, Romas et al. 1996). In addition, IL-1 and TNF $\alpha$ stimulate the production of adhesion molecules, facilitating cell-cell interactions between stromal and haematopoietic cells (Yamate et al. 1997).
The effects of systemic hormones on bone are mediated largely through alterations in the release, by bone marrow cells, of factors that affect the development and activity of bone cells. The marrow cells are ideally suited for this purpose, being in close proximity both to bone surfaces and to blood vessels (Yamazaki \& Eyden 1995). Parathyroid hormone (PTH) and 1,25-dihydroxyvitamin D act in a similar manner to IL-1 and TNF $\alpha$, binding to receptors on stromal/osteoblastic cells and stimulating the production of osteoclastogenic cytokines. It is also possible that PTH-mediated inhibition of osteoblast apoptosis is mediated by modulation of cytokine release from stromal cells.

Oestrogen receptors are expressed by cells in the bone marrow and there is strong evidence to implicate a role for these in the bone loss associated with oestrogen deficiency. In postmenopausal women it has been shown that oestrogen deficiency is associated with increased production, by peripheral blood monocytes, of IL-1, TNF $\alpha$ and GM-CSF and that these changes are abrogated by oestrogen repletion (Ralston et al. 1990, Pacifici et al. 1991, 1993). It was subsequently demonstrated that cytokine secretion by blood monocytes mirrors that of bone marrow monocytes (Pioli et al. 1989, Cohen-Solal et al. 1995); furthermore, increase in bone marrow monocytic production of IL-1 and TNF $\alpha$ has been demonstrated in rodent models after ovariectomy (Kimble et al. 1994, Kitazawa et al. 1994). Changes in IL-1 activity reflect oestrogen-induced alterations in IL-1 receptor antagonist and possibly also soluble IL-1 receptors and IL-1-binding proteins (Pacifici 1999). Consistent with the increase in IL-1 and TNF $\alpha$ activity, oestrogen deficiency is associated with increased production by stromal cells of RANKL, M-CSF, GM-CSF and IL-6, resulting in increased osteoclast precursor proliferation and differentiation, and inhibition of apoptosis. The increase in IL-6 production is associated with increased expression of IL-6 receptor subunit expression on stromal cells in the marrow (Lin et al. 1997). In addition, oestrogen regulates the number and activity of stromal/osteoblastic cells and this is likely to contribute to its effects on osteoclastogenesis (Jilka et al. 1998).

Receptors for many systemic hormones, including those for oestrogens, glucocorticoids, 1,25-dihydroxyvitamin D, thyroid hormones and androgens are also expressed by mature osteoblasts and, in some cases, osteoclasts (Abu et al. 1997a,b, Beavan et al. 2001, Bord et al. 2001b). Glucocorticoids have multiple and complex effects on bone, many of which are likely to be mediated by stromal/osteoblastic cells in the marrow. Thus at physiological concentrations they increase osteoblastic differentiation and regulate the expression of a number of genes including type I collagen, non-collagenous bone proteins, IGF and its binding proteins and TGF $\beta$ and their receptors (Kream \& Lukert 2002). Thyroid hormones and androgens are also important bone regulatory hormones with effects on osteoblastic proliferation and differentiation. The extent to which the effects of these hormones are mediated 
via mature bone cells as opposed to their precursors is unknown and may vary according to the availability of marrow cells at different skeletal sites and at different ages.

\section{Bone remodelling: supply and access of bone cells to remodelling sites}

Bone remodelling involves the removal of mineralised bone by osteoclasts followed by the formation, by osteoblasts, of bone matrix that subsequently becomes mineralised. This process occurs at discrete sites named basic multicellular units (BMUs); although resorption is the initial event, for much of each remodelling cycle resorption and formation occur simultaneously, albeit in different regions of the BMU. The issue of how osteoblasts and osteoclasts gain access to the BMU in cancellous bone is currently a topic of some debate (Parfitt 2001). Quiescent bone surfaces are covered by an endosteal membrane and lining cells and one possible mode of access of osteoblasts and osteoclasts to bone remodelling sites involves digestion of the endosteal membrane and retraction of the lining cells, leaving exposed mineralised bone. However, histological studies indicate that bone remodelling occurs within the confines of a canopy-like structure termed the bone remodelling compartment (BRC) (Hauge et al. 2001) (Fig. 1). Originally this was thought to be vascular in structure and it was suggested that osteoclast precursors gained access to bone via the circulation, as in cortical bone (Parfitt 1998). However, recent evidence indicates that the cells forming the outer wall of the BRC (i.e. those next to the marrow) have an osteoblastic phenotype and it has been suggested that they are derived from the lining cells covering the quiescent bone surface (Hauge et al. 2001). The lack of expression of endothelial markers by these cells does not necessarily exclude a circulatory function (Maniotis et al. 1999); furthermore, marrow sinusoids may communicate with the BRC via small tubular extensions, thus providing potential mechanisms by which circulating osteoclasts can gain access to the bone surface, at least at skeletal sites lacking haematopoietic tissue in the bone marrow.

The mechanisms by which bone cells reach BMUs in cancellous bone thus remain unclear. In those parts of the skeleton where haematopoietic marrow is sparse or absent, the circulatory route is the only route by which osteoclasts can reach bone but this leaves open the question of how osteoblasts gain access to bone, since osteoblastic precursors are not known to circulate. One explanation is that osteoblasts in the BMU are derived from the preosteoblastic cells composing the outer wall of the BRC, marrow stromal cells being the major source of these cells (Parfitt 2001). Alternatively, cells in the canopy may sequentially exhibit a vascular and osteoblastic phenotype, the latter being derived from the former. Further characterisation of the BRC and its relationship to marrow vasculature is required to define more precisely the means by which cells involved in the remodelling process gain access to the cancellous bone surface.

\section{Megakaryocytes, immune cells and bone remodelling}

There is increasing evidence that megakaryocytes play a role in the regulation of bone remodelling. These cells express a number of bone regulatory factors, including RANKL (Kartsogiannis et al. 1999), NMDA-type glutamate receptors (Genever et al. 1999), calcium-sensing receptors (House et al. 1997), osteonectin, osteocalcin (Kelm et al. 1992, Thiede et al. 1994), TGF $\beta$ and their receptors and oestrogen receptors (Bord et al. 2001a). Thrombopoietin, a major regulator of megakaryocytopoiesis, inhibits osteoclastogenesis (Wakikawa et al. 1997) and its over-expression in mouse models is associated with osteopetrosis (Yan et al. 1996). Furthermore, in myelofibrosis, the increase in megakaryocyte population is associated with osteosclerosis (Poulsen et al. 1998).

The observation that oestrogen therapy in postmenopausal women is associated with an increase in megakaryocyte number, which appears to be dose-related, indicates that megakaryocytes may play a role in mediating oestrogen-induced skeletal effects. Bord et al. (2000) reported significantly higher megakaryocyte numbers in the bone marrow of postmenopausal women treated with conventional hormone replacement therapy when compared with baseline, and even greater numbers in a group of postmenopausal women who had received long-term high-dose parenteral oestradiol therapy. In this latter group, high bone mineral density in the spine and proximal femur (Wahab et al. 1997) was associated with histological evidence of increased osteoblast activity, demonstrated by measurement of wall width in iliac crest biopsies (Vedi et al. 1999). Immunolocalisation studies revealed expression of both oestrogen receptor subtypes in megakaryocytes (Fig. 2); furthermore, expression of TGF $\beta 2$ and TGF $\beta$ receptors I and II by these cells was increased when compared with biopsies from a control group, indicating a possible role in the mediation of the observed anabolic skeletal effects (Bord et al. 2001a). The expression by megakaryocytes of RANKL would also be consistent for a role of these cells in the regulation of osteoclastogenesis (Kartsogiannis et al. 1999).

Immune cells in the bone marrow also contribute to the regulation of bone remodelling. $\mathrm{T}$ cells play an important role in ovariectomy-induced bone loss in mice, $\mathrm{T}$ cellderived TNF $\alpha$ up-regulating osteoclastogenesis and causing bone loss via the p55 receptor (Roggia et al. 2001). The magnitude of this effect is reflected by the failure of ovariectomy to induce bone loss in $\mathrm{T}$ cell-deficient athymic nude mice. In addition, $\mathrm{T}$ cells express both RANKL and core binding factor 1 (a transcription factor 


\section{BONE MARROW}

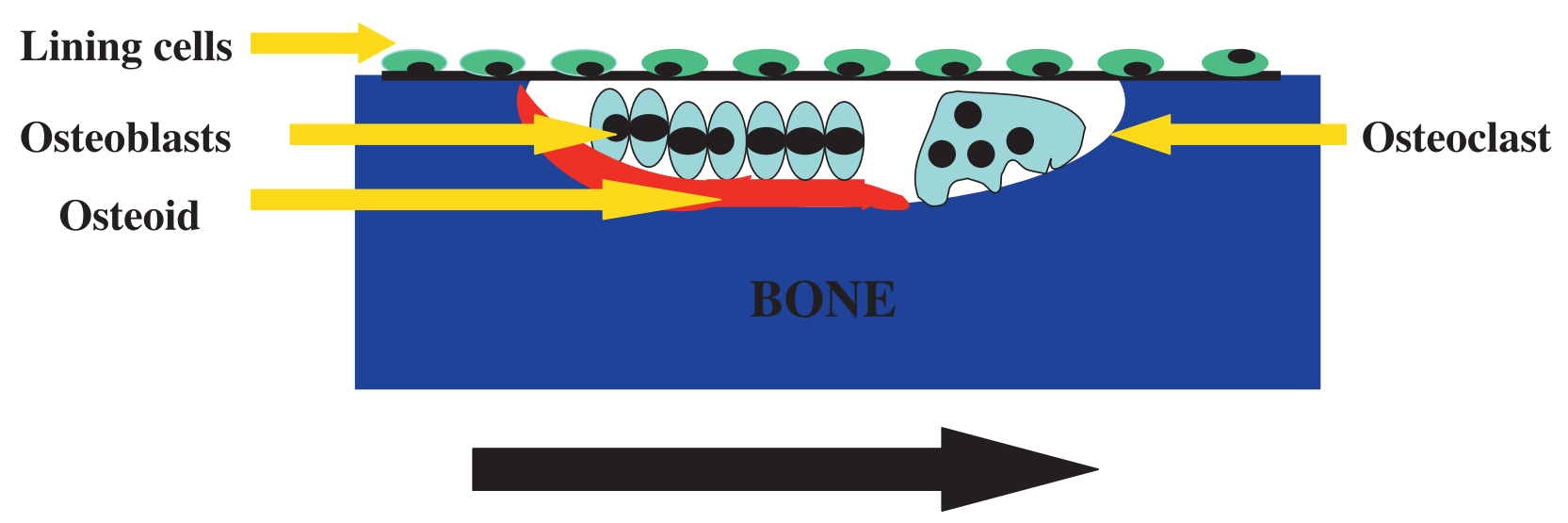

\section{Direction of progression of BMU}

Figure 1 Diagram of a bone remodelling compartment (BRC) as proposed by and reproduced with permission from Hauge et al. (2001). The lining cells (and presumably also endosteal membrane) normally covering the quiescent bone surface become separated from the cancellous bone surface by disruption of the junctions normally present between lining cells and osteocytes embedded in bone, but remain intact during the remodelling cycle. Inside the canopy so formed, osteoclasts derived from circulating precursors resorb bone, and osteoblasts derived from the lining cells of the canopy form new bone within the cavity created by osteoclasts. BMU, basic multicellular unit.

essential for osteoblast development) (Ducy et al. 1997), although the contribution of marrow $\mathrm{T}$ cells relative to stromal cells in the production of these factors is unknown.

\section{Pathological correlates}

Many diseases affecting the bone marrow are associated with bone disease. These include some forms of anaemia, malignant disease and storage or infiltrative diseases. The skeletal abnormalities caused by these conditions and their pathophysiology are diverse and, in many cases, poorly understood. In the context of malignant disease, however, there have been significant advances in understanding the mechanisms by which bone marrow and bone interact in the evolution of skeletal abnormalities.

\section{Anaemias}

Skeletal manifestations are common in both sickle cell anaemia and $\beta$-thalassaemia major (Caffey 1957, Diggs 1967, Parano et al. 1999, Singer \& Vichinsky 1999). In these conditions, bone marrow hyperplasia leads to widening of the medullary cavity; expansion of the medullary space of the skull in combination with orientation of the trabeculae perpendicular to the cortical surface produces the characteristic 'hair-on-end' appearance. There is also disturbance of bone growth and reduction in both cancellous and cortical bone mass. In sickle cell disease, micro- circulatory disturbances and bone infarction may result in episodes of bone pain; other manifestations include the characteristic $\mathrm{H}$-shaped vertebral bodies, caused by infarction of bone in the centre of the vertebral body and the resulting disturbance in bone growth, patchy osteolysis and sclerosis in cancellous bone of long bones, osteonecrosis and osteomyelitis.

\section{Infiltrative and storage disorders}

A number of infiltrative and storage disorders may be associated with bone disease and appear to be related to the presence of abnormal cells in the bone marrow. These conditions include histiocytosis $\mathrm{X}, \quad \beta$-galactosidase deficiency, Niemann-Pick disease and primary oxalosis. Two of the most common of these disorders, namely systemic mastocytosis and Gaucher disease, are discussed briefly below.

In the condition of systemic mastocytosis, abnormal proliferation of mast cells within the bone marrow results in bone disease of varying severity and appearance. Approximately $70 \%$ of patients with the disorder have radiologically manifest disease, the axial skeleton (where red marrow is present) being most commonly affected. Skeletal lesions vary in appearance, poorly demarcated osteolytic or sclerotic areas being most common. However, generalised osteopenia may also occur, sometimes with vertebral compression fractures. The mechanisms by which these skeletal abnormalities are produced have not 

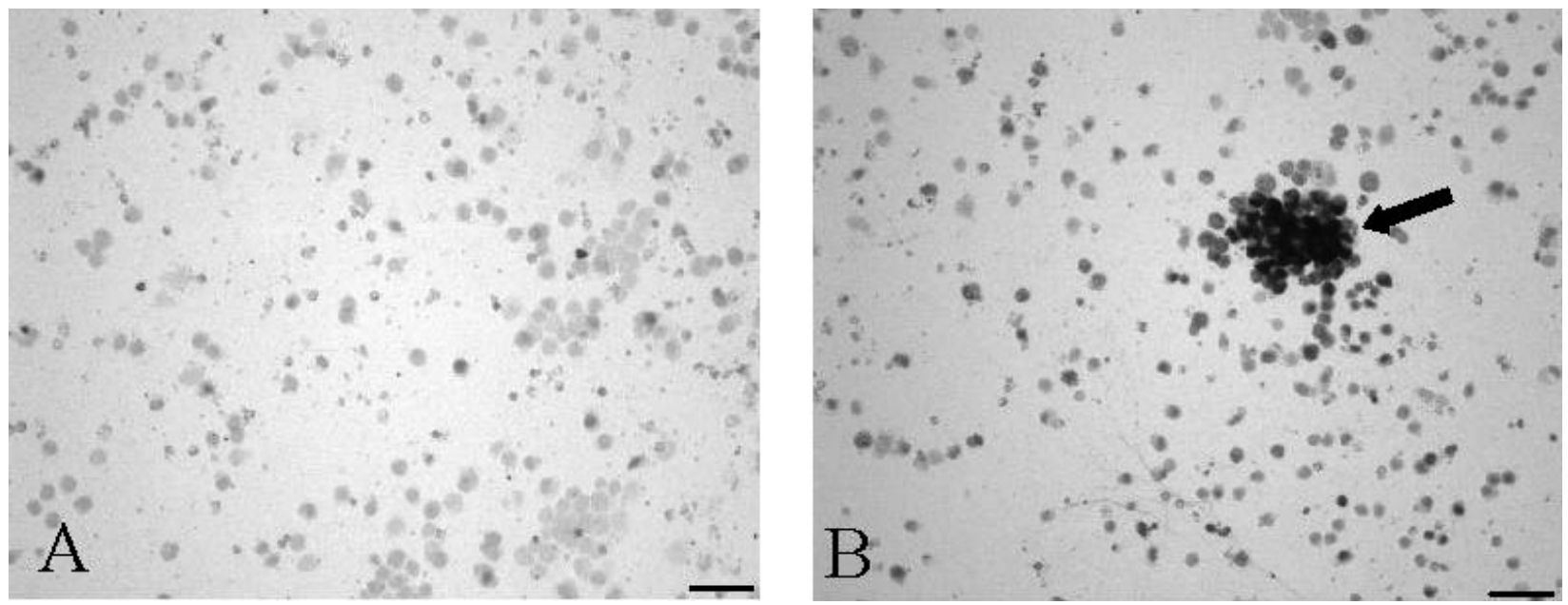

Figure 2 Oestrogen receptor- $\beta$ expression in a human megakaryocyte colony-forming unit (B, arrow). (A) shows a negative control. Bars indicate $50 \mu \mathrm{m}$.

been clearly established; however, production by the mast cells of heparin (Avioli 1975) and IL-6 (Grabbe et al. 1994) may contribute to increased bone resorption, and prostaglandin release may also play a pathogenetic role.

Gaucher disease is an autosomal recessive disorder characterised by defective intracellular hydrolysis of glucosylceramide and related glucosphingolipids, most commonly as a result of mutations of the gene that encodes the lysosomal hydrolase acid $\beta$-glucosidase. Both focal and diffuse skeletal abnormalities occur and may result in serious morbidity (Beutler \& Grabowski 2001). It is believed that both the presence of Gaucher cells in the bone marrow and vascular infarction are important pathogenetic factors but the pathophysiology of the resulting bone disease is poorly understood. Skeletal abnormalities are most commonly found at sites of red marrow and include medullary expansion with Erlenmeyer flask deformity, osteolytic lesions, ischaemic necrosis, sclerosis, periostitis and diffuse bone loss and fractures.

\section{Malignant disease}

Bone marrow is closely implicated in the pathogenesis of malignant bone disease, whether produced by humoral or local mechanisms. Lesions arising from both solid tumours and haematological malignancies most frequently occur at sites where red marrow and vascularity are most prominent, e.g. the vertebrae, ribs and proximal ends of the long bones. The 'Seed and Soil' theory, first proposed in 1889 by Paget (Paget, 1889) is particularly apposite to bone metastases and describes the ability of the bone and bone marrow microenvironment to stimulate the growth of tumour cells. Growth factors produced by cells in the bone marrow and by mature osteoblasts promote the growth of certain tumour cells (Nørgaard et al. 1995) and may also stimulate their chemotaxis. In addition, the process of bone resorption, stimulated by the production of cytokines both by tumour cells and bone marrow cells, releases factors from bone such as TGF $\beta$ s and IGFs, which stimulate tumour growth. TGF $\beta$ also has chemoattractant properties for tumour cells and enhances the production by these cells of PTH-related protein (PTHrP), an important mediator both of humoral and locally mediated malignant bone disease (Guise \& Mundy 1998).

In the case of metastases, both the biological characteristics of the tumour cell and the local microenvironment are important determinants of tumour localisation and growth. Access of metastatic cells to bone is provided mainly by nutrient arteries; the expression of specific adhesion molecules and proteolytic enzymes by these cells enables their passage through the endothelium of sinusoids in the bone marrow. The expression by bone marrow stromal cells of adhesion molecules such as vascular adhesion molecule-1 facilitates the adhesion of tumour cells (Kikuchi et al. 1996) and subsequent development of bone metastases. Although it is likely that a number of bone resorbing factors produced by tumour cells mediate osteolytic metastases, PTHrP is believed to play a prominent role (Wysolmerski \& Broadus 1994); other factors include IL-1, IL-6, TNF and TGFa (Mori 1996). Local bone destruction results from stimulation by PTHrP or these other bone resorbing factors of the production, by stromal cells, of osteoclastogenic factors and hence is mediated by osteoclasts rather than directly by tumour cells.

In multiple myeloma, the malignant plasma cells produce a number of osteoclast-activating factors including IL-1, TNF $\beta$ and IL-6 (Garrett et al. 1987, Cozzolino et al. 1989, Kawano et al. 1989). IL-6, which is produced both by tumour cells and stromal marrow cells, is a major growth factor for myeloma cells (van Zaanen et al. 1996) 
and there is evidence that the production of IL-6 by stromal cells is mediated by adhesion molecules that are expressed on myeloma cells (Lokhorst et al. 1994). Through its stimulatory effect on the generation of osteoclasts precursors, IL-6, together with IL-1 and TNFa, also contributes to the subsequent increase in bone resorption.

\section{Conclusions}

In both health and disease, bone and bone marrow function together in the production of osteoprogenitor and haematopoietic cells and in the regulation of their activity. The mechanisms involved have been only partly characterised and their further definition will provide important new insights into physiological and pathological processes in bone and its microenvironment.

\section{References}

Abu E, Bord S, Horner A, Chatterjee VKK \& Compston JE 1997 a The expression of thyroid hormone receptors in bone. Bone $\mathbf{2 1}$ 137-142.

Abu E, Horner A, Kusec V, Triffitt J \& Compston JE $1997 b$ The localisation of androgen receptors in human bone. Journal of Clinical Endocrinology and Metabolism 82 3493-3497.

Avioli LV 1975 Heparin-induced osteopenia: an appraisal. Advances in Experimental Medicine and Biology 52 375-387.

Beavan SR, Horner A, Bord S \& Compston JE 2001 Co-localisation of glucocorticoid and mineralocorticoid receptors in human bone. Journal of Bone and Mineral Research 16 1496-1504.

Beutler E \& Grabowski GA 2001 Gaucher disease. In The Metabolic and Molecular Bases of Inherited Disease, edn 8, pp 3635-3668. Eds CR Scriver, AL Beaudet, WS Sly \& D Valle. New York: McGraw-Hill.

Bord S, Vedi S, Beavan SR, Horner A \& Compston JE 2000 Megakaryocyte population in human bone marrow increases with oestrogen treatment: a role in bone remodelling? Bone 27 397-401.

Bord S, Beavan S, Ireland D, Horner A \& Compston JE 2001a Mechanisms by which high-dose oestrogen therapy produces anabolic skeletal effects in postmenopausal women: role of locally produced growth factors. Bone 29 216-222.

Bord S, Horner A, Beavan SR \& Compston JE $2001 b$ Estrogen receptors (ER) $\alpha$ and $\beta$ are differentially expressed in growing human bone. Journal of Clinical Endocrinology and Metabolism 86 2309-2314.

Brookes M 1961 The vascular architecture of the mammalian bone cortex. Journal of Anatomy $\mathbf{9 5} 615$.

Caffey J 1957 Colley's anaemia: a review of the roentgenographic findings in the skeleton. American Journal of Radiology 78 381-391.

Cohen-Solal ME, Graulet AM, Guerris J, Denne MA, Bergot C, Morieux C, Sedel L, Kuntz D \& de Vernejoul M-C 1995 Bone resorption at the femoral neck is dependent on local factors in nonosteoporotic late postmenopausal women: an in vitro-in vivo study. Journal of Bone and Mineral Research 10 307-314.

Compston JE 2001 Sex steroids and bone. Physiological Reviews 81 419-447.

Cozzolino F, Torcia M, Aldinucci D, Rubartelli A, Miliani A, Shaw AR, Lansdorp PM \& Di Guglielmo R 1989 Production of interleukin-1 by bone marrow myeloma cells. Blood 74 380-387.

Custer RP 1949 An Atlas of the Blood and Bone Marrow. Philadelphia: Saunders.
Diggs LW 1967 Bone and joint lesions in sickle cell disease. Clinical Orthopaedics and Related Research 52 119-143.

Ducy P, Zhang R, Geoffroy V, Ridall AL \& Karsenty G 1997 Osf2/Cbfa1: a transcriptional activator of osteoblast differentiation. Cell 89 747-754.

Eventov I, Frisch B, Cohen Z \& Hammel I 1991 Osteopenia, hematopoiesis, and bone remodelling in iliac crest and femoral biopsies: a prospective study of 102 cases of femoral neck fractures. Bone 12 1-6.

Fujikawa Y, Quinn JMW, Sabokbar A, McGee JOD \& Athanasou NA 1996 The human osteoclast precursor circulates in the monocyte fracture. Endocrinology 137 4058-4060.

Garrett IR, Durie BG, Nedwin GE, Gillespie A, Bringman T, Sabatini M, Bertolini DR \& Mundy GR 1987 Production of lymphotoxin, a bone-resorbing cytokine, by cultured human myeloma cells. New England Journal of Medicine 317 526-532.

Genever PG, Wilkinson DJP, Patton AJ, Peet NM, Hong Y, Mathur A, Erusalimsky JD \& Skerry T 1999 Expression of a functional $\mathrm{N}$-methyl-D-aspartate-type glutamate receptor by bone marrow megakaryocytes. Blood 93 2876-2883.

Grabbe J, Welker P, Moller A, Dippel E, Ashman LK \& Czarnetzki BM 1994 Comparative cytokine release from human monocytes, monocyte-derived immature mast cells, and a human mast cell line (HMC - ). Journal of Investigative Dermatology 103 504-508.

Guise TA \& Mundy GR 1998 Cancer and bone. Endocrine Reviews 19 $18-54$.

Hauge EM, Qvesel D, Eriksen EF, Mosekilde L \& Melsen F 2001 Cancellous bone remodeling occurs in specialised compartments lined by cells expressing osteoblastic markers. Journal of Bone and Mineral Research 16 1575-1582.

Horner A, Bord S, Kelsall AW, Coleman N \& Compston JE 2001 Tie2 ligands angiopoietin-1 and angiopoietin-2 are co-expressed with vascular endothelial cell growth factor in growing human bone. Bone 28 65-71.

House GM, Kohlmeier L, Chattopadhyay N, Kifor O, Yamaguchi T, Leboff MS, Gowacki J \& Brown EM 1997 Expression of an extracellular calcium-sensing receptor in human and mouse bone marrow cells. Journal of Bone and Mineral Research 12 1959-1970.

Jilka RL 1998 Cytokines, bone remodeling, and estrogen deficiency: a 1998 update. Bone 23 75-81.

Jilka RL, Takahashi K, Munshi M, Williams DC, Robertson PK \& Manolagas SC 1998 Loss of estrogen upregulates osteoblastogenesis in the murine bone marrow: evidence for autonomy from factors released during bone resorption. Journal of Clinical Investigation 101 1942-1950.

Kartsogiannis V, Zhou H, Horwood NJ, Thomas RJ, Hards DK, Wuinn JMW, Noforas P, Ng KW, Martin TJ \& Gillespie MT 1999 Localization of RANKL (receptor activator of NFKB ligand) mRNA and protein in skeletal and extraskeletal tissues. Bone $\mathbf{2 5}$ 525-534.

Kawano M, Tanaka H, Ishikawa H, Nobuyoshi M, Iwato K, Asaoku H, Tanabe O \& Kuramoto A 1989 Interleukin-1 accelerates autocrine growth of myeloma cells through interleukin-6 in human myeloma. Blood 73 2145-2148.

Kelm RJ, Hair GA, Mann KG \& Grant BW 1992 Characterization of human osteoblast and megakaryocyte-derived osteonectin (SPARC). Blood 80 3112-3119.

Kikuchi T, Takeuchi Y, Matsumoto T, Fujita T \& Ogata E 1996 Direct interaction of melanoma cells with bone marrow stromal cells via $\alpha_{4} \beta_{1}$ intergrin/VCAM-1 inhibits osteoblastic differentiation. Journal of Bone and Mineral Research 11 (Suppl 1) S117.

Kimble RB, Vannice JL, Bloedow DC, Thompson RC, Hopfer W, Kung V, Brownfield C \& Pacifici R 1994 Interleukin-1 receptor antagonist decreases bone loss and bone resorption in ovariectomized rats. Journal of Clinical Investigation 93 1959-1967.

Kitazawa R, Kimble RB, Vannice JL, Kung VT \& Pacifici R 1994 Interleukin-1 receptor antagonist and tumor necrosis factor binding 
protein decrease osteoclast formation and bone resorption in ovariectomized mice. Journal of Clinical Investigation 94 2397-2406.

Kream BE \& Lukert BP 2002 Clinical and basic aspects of glucocorticoid action in bone. In Principles of Bone Biology, pp 723-740, edn 2. Eds JP Bilezikian, LG Raisz \& GA Rodan. San Diego: Academic Press.

Krempien B, Lemminger FM, Ritz E \& Weber E 1978 The reaction of different skeletal sites to metabolic bone disease - a micromorphometric study. Klinische Wochenschrift 56 755-759.

Lin SC, Yamate T, Taguchi Y, Borba VZ, Girasole G, O'Brien CA, Bellido T, Abe E \& Manolagas SC 1997 Regulation of the gp80 and gp130 subunits of the IL-6 receptor by sex steroids in the murine bone marrow. Journal of Clinical Investigation $\mathbf{1 0 0}$ 1980-1990.

Lokhorst HM, Lamme T, de Smet M, Klein S, de Weger R, van Oers R \& Bloem AC 1994 Primary tumour cells of myeloma patients induce interleukin-6 secretion in long-term bone marrow cultures. Blood 84 2269-2277.

Maniotis AJ, Folberg R, Hess A, Seftor EA, Gardner LM, Pe'er J, Trent JM, Meltzer PS \& Hendrix MJ 1999 Vascular channel formation by human melanoma cells in vivo and in vitro: vasculogenic mimicry. American Journal of Pathology 155 739-752.

Manolagas SC \& Jilka RL 1995 Bone marrow, cytokines and bone remodeling - emerging insights into the pathophysiology of osteoporosis. New England Journal of Medicine 332 305-311.

Meunier P, Aaron J, Edouard C \& Vignon G 1971 Osteoporosis and the replacement of cell populations of the marrow by adipose tissue: a quantitative study of 84 iliac bone biopsies. Clinical Orthopaedics and Related Research 80 147-154.

Mori H, Aoki K, Katayama I, Nishioka K \& Umeda T 1996 Humora hypercalcaemia with elevated plasma PTHrP, TNF alpha and IL-6 in cutaneous squamous cell carcinoma. Journal of Dermatology 23 460-462.

Nørgaard P, Hougaard S, Poulsen HS \& Spang-Thomsen M 1995 Transforming growth factor- $\beta$ and cancer. Cancer Treatment Reviews 21 367-403.

Owen M 1988 Marrow stromal cells. Journal of Cell Science 10 63-76.

Pacifici R 1999 Aging and cytokine production. Calcified Tissue International 65 345-351.

Pacifici R, Brown C, Puscheck E, Friedrich E, Slatopolsky E, Maggio D, McCracken R \& Avioli LV 1991 Effect of surgical menopause and estrogen replacement on cytokine release from human blood mononuclear cells. PNAS 88 5134-5138.

Pacifici R, Vannice JL, Rifas L \& Kimble RB 1993 Monocytic secretion of interleukin-1 receptor antagonist in normal and osteoporotic women: effect of menopause and estrogen/progesterone therapy. Journal of Clinical Endocrinology and Metabolism $\mathbf{7 7}$ 1135-1141.

Paget S 1989 The distribution of secondary growths in cancer of the breast. Cancer and Metastasis Reviews 8 98-101.

Parano E, Pavone V, Di Gregorio F, Pavone P \& Trifiletti RR 1999 Extraordinary intrathecal bone reaction in $\beta$-thalassaemia intermedia. Lancet 354922.

Parfitt AM 1998 Osteoclast precursors as leukocytes: importance of the area code. Bone 23 491-494.

Parfitt AM 2001 The bone remodeling compartment: a circulatory function for bone lining cells. Journal of Bone and Mineral Research 16 1583-1585.

Pioli G, Girasole G, Pedrazzoni M, Sansoni P, Davoli L, Ciotti G, Mantovani A \& Passeri M 1989 Spontaneous release of interleukin 1 (IL-1) from medullary mononuclear cells of Pagetic subjects. Calcified Tissue International 45 257-259.

Poulsen LW, Melsen F \& Bendix K 1998 A histomorphometric study of haematological disorders with respect to marrow fibrosis and osteosclerosis. APMIS: Acta Pathologica, Microbiologica, et Immunologica Scandinavica 106 495-499.
Ralston SH, Russell RGG \& Gowen M 1990 Estrogen inhibits release of tumor necrosis factor from peripheral blood mononuclear cells in postmenopausal women. Journal of Bone and Mineral Research 5 983-988.

Roggia C, Weitzmann MN, Cenci S, Toraldo G, Kindle J \& Pacifici R 2001 Estrogen deficiency causes bone loss through upregulated T cell production of TNF alpha. Bone 28 (Suppl) S79.

Romas E, Udagawa N, Zhou H, Tamura T, Saito M, Taga T, Hilton DJ, Suda T, Ng KW \& Martin TJ 1996 The role of gp-130mediated signals in osteoclast development: regulation of interleukin 11 production by osteoblasts and distribution of its receptor in bone marrow cultures. Journal of Experimental Medicine 183 2581-2591.

Rozman C, Feliu E, Berga L, Reverter JC, Climent C \& Ferran MJ 1989 Age-related variations of fat tissue fraction in normal human bone marrow depend both on size and number of adipocytes: a stereological study. Experimental Hematology 17 34-37.

Singer ST \& Vichinsky EP 1999 Bone disease in $\beta$-thalassaemia. Lancet 354 881-882.

Tanaka S, Takahashi N, Udagawa N, Tamura T, Akatsu T, Stanley ER, Kurokawa T \& Suda T 1993 Macrophage colony-stimulating factor is indispensable for both proliferation and differentiation of osteoclast progenitors. Journal of Clinical Investigation 91 257-263.

Teitelbaum SL 2000 Bone resorption by osteoblasts. Science $\mathbf{2 8 9}$ 1504-1508.

Thiede MA, Smock SL, Peterson DN, Grasser WA, Thompson DD \& Nishimoto SK 1994 The presence of messenger-ribonucleic-acid encoding osteocalcin, a marker of bone turnover, in bone marrow megakaryocytes and peripheral blood platelets. Journal of Endocrinology 135 929-937.

Udagawa N, Takahashi N, Katagiri T, Tamura T, Wada S, Findlay DM, Martin TJ, Hirota H, Tada T, Kishimoto T et al. 1995 Interleukin (IL)-6 induction of osteoclast differentiation depends on IL-6 receptors expressed on osteoblastic cells but not on osteoclast progenitors. Journal of Experimental Medicine 182 1461-1468.

Van Dyke D 1967 Similarity in distribution of skeletal blood flow and erythropoietic marrow. Clinical Orthopaedics and Related Research $\mathbf{5 2}$ $37-51$.

Vedi S, Compston JE, Ballard P, Bord S, Cooper ACV \& Purdie DW 1999 Bone remodelling and structure in postmenopausal women treated with long-term, high-dose oestrogen therapy. Osteoporosis International 10 52-58.

Wahab M, Ballard P, Purdie DW, Cooper A \& Wilson JC 1997 The long-term effects of oestradiol implantation on bone mineral density in post menopausal women who have undergone hysterectomy and bilateral oophorectomy. British Journal of Obstetrics and Gynaecology 104 728-731.

Wakikawa T, Shioi A, Hino M, Inaba M, Nishizawa Y, Tatsumi N, Hirotoshi M \& Otani S 1997 Thrombopoietin inhibits in vitro osteoclastogenesis. Endocrinology 138 4160-4166.

Wysolmerski JJ \& Broadus AE 1994 Hypercalcaemia of malignancy: the central role of parathyroid hormone-related protein. Annual Review of Medicine 45 189-200.

Yamate T, Mocharla H, Taguchi Y, Igietseme JU, Manolagas SC \& Abe E 1997 Osteopontin expression by osteoclast and osteoblast progenitors in the murine bone marrow: demonstration of its requirement for osteoclastogenesis and its increase after ovariectomy. Endocrinology 138 3047-3055.

Yamazaki K \& Eyden BP 1995 A study of intercellular relationships between trabecular bone and marrow stromal cells in the murine femoral epiphysis. Anatomical Embryology 192 9-20.

Yan XQ, Lacey D, Hill D, Chen Y, Fletcher F, Hawley RG \& McNiece IK 1996 A model of myelofibrosis and osteosclerosis in mice induced by overexpressing thrombopoietin (mpl-ligand): reversal of disease by bone marrow transplantation. Blood $\mathbf{8 8}$ 402-409.

Yasuda H, Shima N, Nakagawa N, Yamaguchi K, Kinosaki M, Mochizuki S-I, Tomoyasu A, Yano K, Goto M, Murakani A et al. 
1998 Osteoclast differentiation factor is a ligand for osteoprotegerin/ osteoclastogenesis-inhibitory factor and is identical to TRANCE/ RANKL. PNAS 95 3597-3602.

van Zaanen HCT, Koopmans RP, Aarden LA, Rensink HJAM, Stouthard JML, Warnaar SO, Lokhorst HM \& van Oers MHJ 1996

Endogenous interleukin-6 production in multiple myeloma patients treated with chimeric monoclonal anti-IL6 antibodies indicates the existence of a positive feed-back loop. Journal of Clinical Investigation 98 1441-1448.

Received 7 February 2002

Accepted 19 March 2002 